\title{
Childhood obesity and community food environments in Alabama's Black Belt region
}

\author{
Y. Li, ${ }^{\star}$ L. E. Robinson, $†$ W. M. Carter, ${ }^{\star}$ R. Gupta \\ *Department of Geology and Geography, Auburn University, Auburn, AL, USA \\ $\uparrow$ School of Kinesiology, University of Michigan, Ann Arbor, MI, USA, and \\ ¥Ann and Robert H. Lurie Children’s Hospital of Chicago, Northwestern Feinberg School of Medicine, Chicago, IL, USA
}

Accepted for publication 1 September 2014

\author{
Keywords \\ Black Belt region, \\ childhood obesity, \\ community food \\ environments, mixed \\ methods \\ Correspondence: \\ Yingru Li, Petrie 210, \\ Auburn University, \\ Auburn, AL 36849-5412, \\ USA \\ E-mail: \\ yingru.li@auburn.edu
}

\begin{abstract}
Background Childhood obesity has been rising rapidly in the USA. The rate is higher among those at a lower socioeconomic status and racial/ethnic minority groups. In Alabama, nearly half of the children from rural African American families are overweight or obese. Studies suggest that children's eating behaviours and weight could be influenced by surrounding food environments. The purpose of this paper is to assess the community food environment and examine the associations with childhood obesity in Alabama's Black Belt region.

Methods This research uses both qualitative and quantitative methods. Weight status of 613 African American students in four elementary schools in a rural county of Alabama was assessed. We examined community food environments around children's home through GIS (Geographic Information System) and statistical methods. The interrelations between children's weight and community food environments are explored with multi-level models.

Results Approximately $42.1 \%$ of surveyed children were overweight or obese, much higher than the national average, $30.6 \%$. In Model 1 , convenience stores $(3.44 ; P<0.01)$, full service restaurants (8.99; $P<0.01)$ and supermarkets $(-37.69 ; P<0.01)$ were significantly associated with the percentile of body mass index. Fast food stores $(-0.93 ; P=0.88)$ were not related to children's weight. In Model 2 , the additions of sociodemographic factors and school effects cause significant changes of the relationships between children's weight and four types of food outlets. The percentage of African American population $(90.23, P<0.01)$ and school $(6.68, P<0.01)$ were positively associated with children's weight; while median household income $(-39.6 ; P<0.01)$ was negatively related to it. Conclusion Children's weight is influenced by community food environments, sociodemographic factors and school context. Findings suggest that policymakers and planners need to improve community food environments of low-income minority communities. Parents and schools should pay more attention to reduce the negative impacts of food environments on children.
\end{abstract}

\section{Introduction}

In the USA, childhood obesity has been rising rapidly in all population groups (Lanigan 2010). However it disproportionally affects those from lower socioeconomic status (SES, Oreskovic et al. 2009) and racial/ethnic minority groups. This is perhaps most evident in the Black Belt region (BBR), a crescent-shaped area extending from south-west Tennessee through Mississippi, Alabama and Georgia, where a high percentage of low-income rural African American population resides and socioeconomic disparities abound (Davy et al. 2004). In some of Alabama's rural schools, over 50\% of the 
children are overweight/obese (Barone 2005) compared with $30.6 \%$ nationally. To date, the underlying factors for these disparities within the BBR remain poorly understood.

Environmental factors play a key role in obesity-related behaviours (Gordon-Larsen et al. 2006) and children's weight. The vulnerability to environmental factors increases obesity risks of rural African American children through community and school environments (Grow et al. 2010). Children's eating behaviours could be influenced by placement and availability of restaurants and retail food stores (Morland \& Evenson 2009). In the last two decades, the increased availability of cheap, convenient, energy-dense food has been considered as one of the reasons of the rising trajectory of obesity rates in the USA (Holsten 2008). Poor (i.e. low-SES) communities tend to have more fast food restaurants within walking distance than middle to higher-SES communities (Burns \& Inglis 2007). Retail food stores in higher-SES neighbourhoods offer more food choices and nutritious food than low-SES neighbourhoods (Glanz et al. 2012). Besides community-level demographics, previous studies have also identified the context effect of schools, and students' obesity levels vary significantly among schools (Cory 2007; Procter et al. 2008). The context effects of schools and community-level demographics might both influence the associations between unequal food environments and children's weight status. In the USA, unequal access to healthy food has been revealed, while fewer studies have assessed the impacts of these disparities on diet-related health outcomes (Morland \& Evenson 2009). In addition, the research findings of the relationship between community food environments and obesity rates are inconsistent (Holsten 2008).

The community food environment at a location is defined as 'the number, type, location, and accessibility of food outlets' (Moore et al. 2008). The previous studies frequently use density, or proximity, or both to measure food environments. For example, Moore and colleagues (2008) assessed the local food environment with the density of supermarkets within one mile of participant's home and local residents' perceptions of the availability of healthy food. They found participants with access to supermarkets tended to have a healthy diet. Burdette and Whitaker (2004) examined the association of overweight children and the street distance between each child's home and the nearest fast food restaurant but did not find significant relationship. Frank and colleagues (2012) evaluated food environments based on the density of fast food restaurants within 0.5 mile and the distance to supermarkets from each block group. However, people live in a continuous world and individual's exposure to spaces cannot be limited arbitrarily by distance or boundaries (Mathews 2012). The habitual range of children is a contiguous space extending around a child's home and school (McMurray et al. 1999). According to the distance decay function of geography (Tobler 1970), the influence of the environment on children declines with increasing distance from the centre point, for example home. The spatial analysis is needed to capture the distance decay feature and assess the spatially continuous food environment (Mathews 2012).

This study fills the gap in the literature by addressing the following research objectives: (i) to examine the patterns of childhood obesity in one of the poorest regions of the USA, the BBR; (ii) to quantify the spatially continuous community food environments by integrating GIS and statistical techniques; and (iii) to assess the impacts of unequal food environments on childhood obesity. We hypothesize that: (i) children living in healthier food environments have lower chance of being overweight or obese than those living in poorer food environments; and (ii) the associations between food environments and children's weight status would be changed if controlling for sociodemographic characteristics and school effects as the quality of food environments is significantly related to the context effects of communities and schools.

\section{Methodology}

\section{Study area and survey measures}

A rural BBR county in the Southeast was chosen as the study case because it is mostly rural with high rates of poverty and African American population (Fig. 1). According to the 2010 census, the population of the county was 21452 with mixed races, $82.6 \%$ African American, 15.5\% White and 1.9\% other races. The median household income was $\$ 21180$, much lower than that of Alabama, $\$ 43160$, and that of the USA, \$53 146. About $26.6 \%$ of families and $32.8 \%$ of the population were below the poverty line, with $43.8 \%$ of the poor people under age 18 (United States Census Bureau 2010).

Assessments were completed in four elementary schools in March 2013. The study was approved by the Institutional Review Board at Auburn University. The targeted samples were children enrolled in these schools between grades Kindergarten and Five. Consent was obtained on 646 children. Complete data were collected on 613 children and used for analyses. The children, all African American, were between the ages of 4-13 years and the mean age was 8 years (s.d. $=1.8)$. The gender distribution was even, with $49.1 \%$ female and $50.9 \%$ male. The sample size distribution of block group level was relatively balanced, ranging between 9 and 69 , and the median sample size is 30 . 

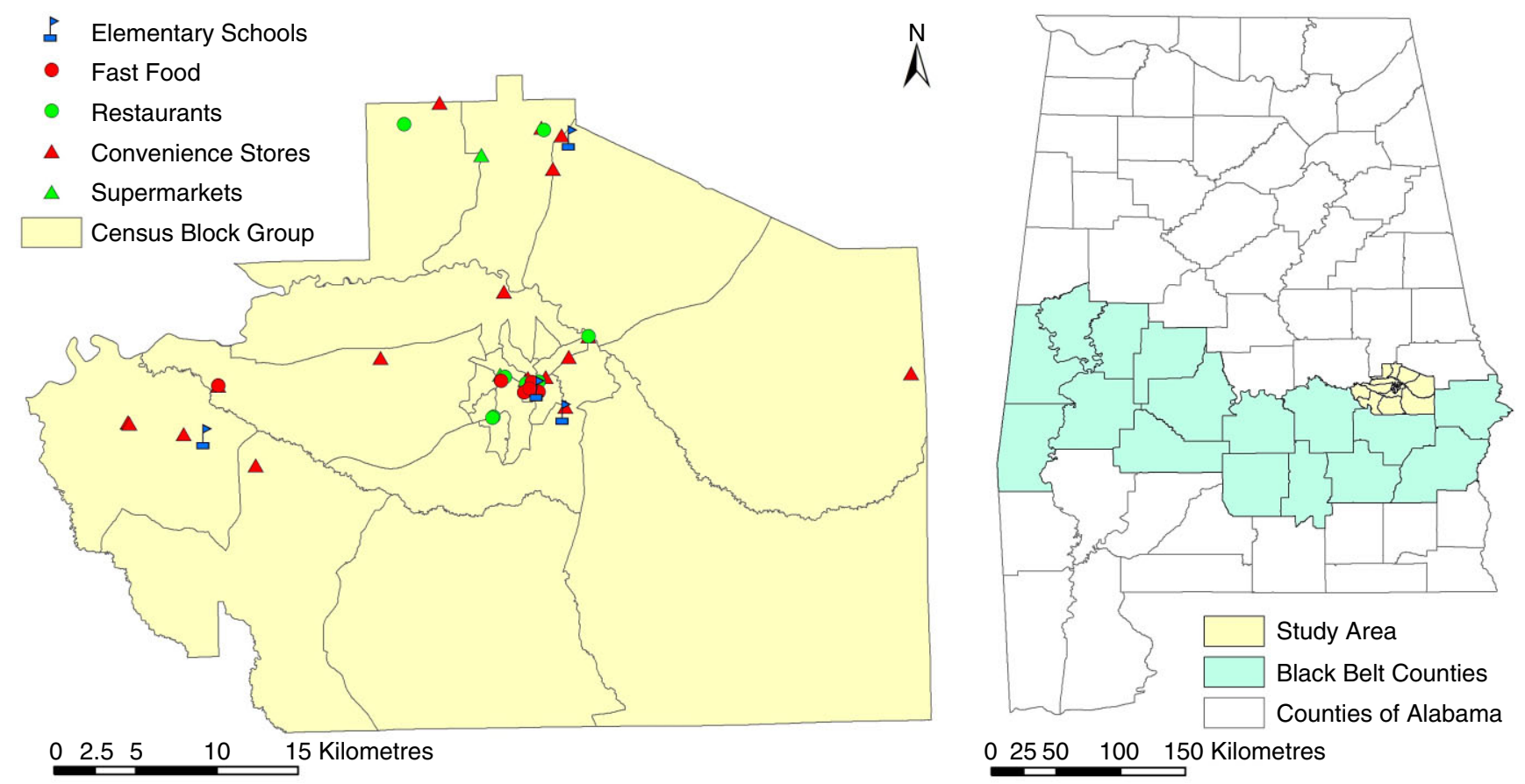

Figure 1. Study area.

Among 20 block groups of this county, one had nine samples, 10 had 11-30 surveyed students each, and nine had more than 30 samples each.

The survey incorporated an array of individual-level measures of weight, height, and sociodemographics such as age and gender. Percentile of body mass index (BMI), the most commonly used measure in the USA (Kowalski et al. 2004), is chosen to assess the size and growth patterns of individual children. BMI was obtained by anthropometry. Both self-report and measured anthropometric measures were used to calculate BMI according to the sex and age-specific growth charts from the Centers for Disease Control and Prevention and assigned the following percentile classifications: 'normal weight' $(\leq 84 \mathrm{th})$, 'overweight' (85th-94th) and 'obese' ( $>95$ th) (Centers for Disease Control and Prevention 2012).

\section{Food environment assessment}

The current measurements of community food environments in the literature have the following limitations. The approach of proximity assumes people would always eat or shop at the nearest food outlets while ignoring other alternatives. The density-based measures only assess the food environment within an arbitrary boundary and neglect the food outlets outside of the boundary. It is also subject to a famous geo- graphic concept, the Modifiable Areal Unit Problem (MAUP). MAUP may cause statistical bias because the geographic measures or associations between variables might change with different definition of boundaries or spatial scales (Zhang et al. 2011). In addition, the community food environment is determined by all types of food outlets together rather than certain types of food stores separately.

This research proposes ways of solving these problems and comprehensively measuring the community food environment. First, a widely used retail model, Huff's model, was applied to estimate the probabilities that children patronize different types of food outlets in the study area from their home. Huff assumed the probability that a customer patronizes a store is directly associated with its size, and inversely related to the distance from the store (Huff 1963; Li \& Liu 2012). The probability that child $i$ patronizes store $j$ is calculated with this equation:

$P_{i j}=\left(S_{j} / D_{i j}^{\beta}\right) /\left(\sum_{j=1}^{n}\left(S_{j} / D_{i j}^{\beta}\right)\right)$

$S_{j}$ is the attraction (store size) of store $j ; D_{i j}$ is the street distance from home of child $i$ to store $j ; \beta$ is a parameter that reflects the effect of distance on shopping and we used the default parameter in this research, 2 ; and $n$ is the number of stores. 
Four types of food outlets are included in this study, convenience store, fast food store, supermarket and full service restaurant. The former two types of stores mostly sell high-calorie and unhealthy food, while the latter two have more choices of food and offer healthy and nutritious food. We included all of these four types of food outlets listed on the local Yellow Book, 22 convenience stores, seven fast food stores, five supermarkets and 11 full service restaurants. Food outlets and children's home addresses were geocoded and distances from stores to children's home were obtained with ArcGIS. The sizes of these stores were measured on Google Earth.

Second, an overall index of measuring the food environment was obtained to assess the community food environment around each child. We standardized the probabilities that children patronize a certain food outlet by calculating the $z$ scores with the following equation:

$z_{i j}=\left(P_{i j}-\overline{P_{i j}}\right) / S D$

where $z_{\mathrm{ij}}$ is the $z$ score of the probability that child $i$ patronizes store $j$. This score is able to reflect the rank of each child among the sampling group (Franzini et al. 2009) in terms of the probability of patronizing store $j$. A larger score reflects a higher rank.

A composite score of a certain type of food outlet was calculated for each child by summing $z$ scores of probabilities that this child patronizes stores of this type. This composite score indicates the rank of the probability that this child patronizes this type of food outlet among sampled children. Four composite scores were obtained for each child, and were named as index of convenience store, index of fast food, index of supermarket and index of restaurant. These original composite indices were used as independent variables in statistical analysis to examine their impacts on children's weight status. A larger index indicates a higher probability that a child patronizes a certain type of stores.

As supermarkets and full service restaurants have been demonstrated as healthier food sources, the larger composite scores of these two types of food outlets indicate better food environments. In contrast, for unhealthy convenience stores and fast food restaurants, larger composite scores indicate poorer food environments. In order to make the ranks consistent for all types of stores, we reversed the ranks of convenience stores and fast food restaurants by multiplying the original composite scores by -1 . A composite index of the community food environment for each child was obtained by summing $z$ scores of the composite scores of supermarkets and full service restaurants as well as $z$ scores of the transformed composite scores of convenience stores and fast food restaurants. The overall score is called food environment score (FES). A larger FES indicates a better food environment.

\section{Statistical analysis}

Multi-level regression was applied to further examine the association between food environments and children's weight status. Data were sorted and organized to three levels, individual, block group and school levels. Variables were summarized in Table 1. The dependent variable is the percentile of BMI. There are two sets of independent variables. The first set of independent variables measures community food environments, including indices of convenience store, fast food, supermarket and full service restaurant. For the first two types of stores, smaller indices indicate healthier food environments; for

\begin{tabular}{|c|c|c|}
\hline Class & Type & Variables \\
\hline $\begin{array}{l}\text { Dependent } \\
\text { variable }\end{array}$ & Weight status & Percentile of BMI \\
\hline \multirow[t]{7}{*}{$\begin{array}{l}\text { Independent } \\
\text { variables }\end{array}$} & $\begin{array}{l}\text { Community food } \\
\text { environment }\end{array}$ & $\begin{array}{l}\text { Composite score of probabilities that } \\
\text { a child patronizes convenience stores }\end{array}$ \\
\hline & & $\begin{array}{l}\text { Composite score of probabilities that } \\
\text { a child patronizes fast food restaurants }\end{array}$ \\
\hline & & $\begin{array}{l}\text { Composite score of probabilities that } \\
\text { a child patronizes full service restaurants }\end{array}$ \\
\hline & & $\begin{array}{l}\text { Composite score of probabilities that } \\
\text { a child patronizes supermarket }\end{array}$ \\
\hline & Block group & $\%$ of African American population (quartile) \\
\hline & demographics & $\begin{array}{l}\text { Median household income of block } \\
\text { group (quartile) }\end{array}$ \\
\hline & School & $\begin{array}{l}\text { Four schools are coded as } 1,2,3,4 \text { based } \\
\text { on the distance to the downtown area }\end{array}$ \\
\hline
\end{tabular}

Table 1. Dependent and independent variables

BMI, body mass index. 
the latter two, larger indices reflect better food environments. The second set of variables reflects the community-level demographics and school effects. Community-level demographics include the percentage of African American population of block group in 2010 and the median household income of census tract in 2012. Recent block group-level household income data are not available in Alabama, and therefore we used census tract data instead. These census data were downloaded from the Census Bureau (http://www.census.gov). Both demographic factors were categorized by quartiles in statistical analysis. School context was indicated by an ordinal variable and four schools are coded as 1, 2, 3 and 4 according to their distances to downtown area where many food outlets concentrate. Two multi-level regression models were constructed. With the first set of independent variables only, Model 1 examines the relationship between food environments and children's weight status. With both the first and second sets of independent variables, Model 2 investigates the interaction of food environments and children's weight status when controlling for communitylevel demographics and school effects.

\section{Results}

Table 2 summarizes the percentages of obese and overweight children among various groups. Not surprisingly, $42.1 \%$ of the surveyed children were overweight or obese, much higher than the national average, $30.6 \%$. The rate that boys were overweight or obese was $43 \%$, higher than that of girls, $41.2 \%$, because girls were more likely to make efforts to lose weights compared with their boy peers (Field et al. 1999). Regarding different age groups, $33.9 \%$ of 4 - to 6-year-old children are overweight or obese. However, $44.3 \%$ of 7 -year-old or older children have weight problems.

Table 3 presents the analytical results of two multi-level regression models. Model 1 includes four variables measuring the food environments, which reflect the probabilities that children patronize four types of food outlets. This model purely examines influences of community food environments on children's weight. Except the index of fast food store $(-0.93 ; P=$ $0.88)$, all other three indices display significant associations with the percentile of BMI. As we expect, the index of convenience store $(3.44 ; P<0.01)$ is positively related to children's weight status, illustrating that children have higher risk of being overweight or obese if their families patronize convenience stores more often. The index of supermarket $(-37.69 ; P<0.01)$ is negatively associated to the dependent variable, indicating that children more accessible to supermarkets tend to have healthy weight status. While contrary to our expectation, children with higher probabilities of patronizing full service restaurants (8.99; $P<0.01)$ tend to be overweight or obese.

In Model 2, the percentage of African American population, median household income and school were added to reveal how community-level demographical factors and school effects influence the interaction between children's weight status and
Table 2. Sample statistics

Table 3. Results of multi-level regression

\begin{tabular}{lllll}
\hline & & & $\begin{array}{l}\text { \% of } \\
\text { obese or } \\
\text { overweight }\end{array}$ & Sample size \\
\hline All & Coding & N/A & $42.1 \%$ & 613 \\
Gender & All & 1 & $41.2 \%$ & 301 \\
Age & Girl & 2 & $43 \%$ & 312 \\
& Boy & N/A & $33.9 \%$ & 130 \\
& $4-6$ & N/A & $44.3 \%$ & 300 \\
& $7-9$ & N/A & $44.3 \%$ & 183 \\
\hline
\end{tabular}

\begin{tabular}{|c|c|c|c|c|}
\hline \multirow[b]{2}{*}{ Variable } & \multicolumn{2}{|l|}{ Model 1} & \multicolumn{2}{|l|}{ Model 2} \\
\hline & Coefficient & $P$ value & Coefficient & $P$ value \\
\hline Convenience store & 3.44 & $<0.01$ & -1.76 & $<0.01$ \\
\hline Fast food & -0.93 & 0.88 & 4.52 & 0.2 \\
\hline Restaurant & 8.99 & $<0.01$ & -3.45 & $<0.01$ \\
\hline Supercentre & -37.69 & $<0.01$ & -9.69 & $<0.01$ \\
\hline$\%$ of African American & & & 90.23 & $<0.01$ \\
\hline Median household income & & & -39.6 & $<0.01$ \\
\hline School & & & 6.68 & $<0.01$ \\
\hline
\end{tabular}




\begin{tabular}{llllr}
\hline $\begin{array}{l}\text { \% African American of block } \\
\text { groups }\end{array}$ & Students & FES $<-\mathbf{1}$ & $\mathbf{- 1 < \text { FES } < \mathbf { 1 }}$ & FES $>\mathbf{1}$ \\
\hline$>50 \%$ & 563 & $11.37 \%$ & $81.35 \%$ & $7.28 \%$ \\
$<50 \%$ & 50 & 0 & $74.00 \%$ & $26.00 \%$ \\
\hline Median household income & Students & FES $<-\mathbf{1}$ & $\mathbf{- 1}<$ FES $<\mathbf{1}$ & FES $>\mathbf{1}$ \\
\hline$>\$ 30000$ & 251 & $16.73 \%$ & $72.11 \%$ & $11.16 \%$ \\
$<\$ 30000$ & 362 & $6.36 \%$ & $86.46 \%$ & $7.18 \%$ \\
\hline
\end{tabular}

Table 4. Racial composition, household income, and food environment scores food environments. The addition of the three variables causes remarkable changes of the relationships between children's weight status and four indices. Different from Model 1, the indices of convenience stores $(-1.76 ; P<0.01)$, full service restaurants $(-3.45 ; P<0.01)$ and supermarkets $(-9.69 ; P<0.01)$ are all negatively associated with children's percentile of BMI. The index of fast food stores is still insignificant. For community-level demographical factors and school effects, all three variables have significant impacts on children's weight as expected. Children living in low-income neighbourhoods (-39.6; $P<0.01)$ with high percentages of African American population $(90.23, P<0.01)$ have higher risk of being overweight or obese. Children tend to have healthy weight status if their school $(6.68, P<0.01)$ has better access to healthy food.

We further examined the associations of the overall FES and community-level demographic factors, percentages of African American population and median household income (Table 4). FES ranges from -5.35 to 5.3 , a larger score reflecting healthier food environment. In the block groups where White people are majority, 26\% of surveyed children's FES are over 1; none of them is lower than -1 . However, in the block groups with African American population as majority, only $7.28 \%$ of surveyed children have FESs over 1, while $11.37 \%$ of them are lower than -1 . In the block groups with median household income higher than $\$ 30000,11.16 \%$ of children's FESs are over 1 , and $16.73 \%$ are lower than -1 . In those block groups with median household income lower than $\$ 30$ 000, 7.18\% of children's FESs are over 1 , and $6.36 \%$ are lower than -1 . Apparently, lowincome and African American communities have poorer food environment surrounding children compared with middleincome and White communities.

\section{Discussion}

Based on the recently collected data from four elementary schools and food outlets in a rural county of Alabama, this study analyses the patterns of childhood obesity, assesses community food environments, and examines the interactions between socioeconomic disparities, childhood obesity and food environ- ments. In this research, the prevalence of overweight or obese was higher among boys as compared with girls, consistent with the previous studies (Field et al. 1999; Velde et al. 2007). Overweight or obesity rate among children aged $7-13$ was $10 \%$ higher than those aged 4-6. This result raises cautions of the potential factors causing the sharp increase in overweight or obese rate regarding age difference.

The results of food environment assessment and statistical analysis fully support two hypotheses. Children living in healthier food environments have lower chance of being overweight or obese than those living in poorer food environments (Hypothesis 1). This finding is generally in line with previous evidences that children's BMI are highly influenced by their accessibility to healthy food (Leung et al. 2011; Carroll-Scott et al. 2013). Nonetheless, children's weight status is also significant to sociodemographic factors and school effects. The interactions of food environments and children's weight status are greatly changed when controlling three variables, percentage of African American population, median household income and school effects (Hypothesis 2). In this county, the quality of community food environments is greatly associated with sociodemographic factors. All seven fast food stores and 20 out of 22 convenience stores are located in the block groups where African American population is majority (Fig. 2). More seriously, there are no food stores in the three block groups at the southeast corner of the county, where more than $85 \%$ of population is African American. In contrast, the two block groups with majority of White population have one supermarket and two full service restaurants. All other full service restaurants and supermarkets are clustered in the downtown area for benefiting the agglomeration effects of retail stores. The majority of fast food and convenience stores are located within block groups with median household income lower than $\$ 30000$ (Fig. 3). Obviously, middle-income and White communities have more and better food choices than low-income African American communities. Furthermore, the context effect of schools is significant in this study and the overweight and obese rates of African American students vary from $35.8 \%$ to $57.9 \%$ among four schools. The school located in the area where White popu- 
Figure 2. Racial disparity and community food environments.

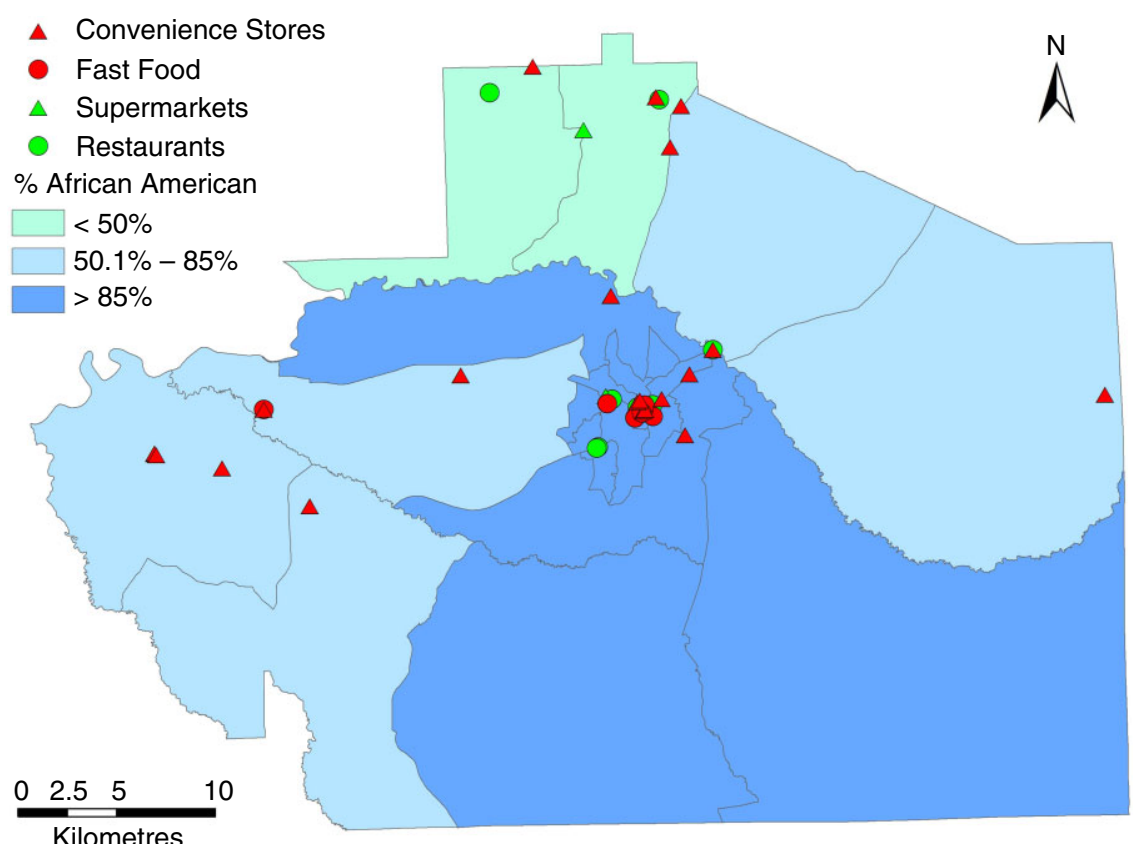

Kilometres
Figure 3. Income inequality and community food environments.

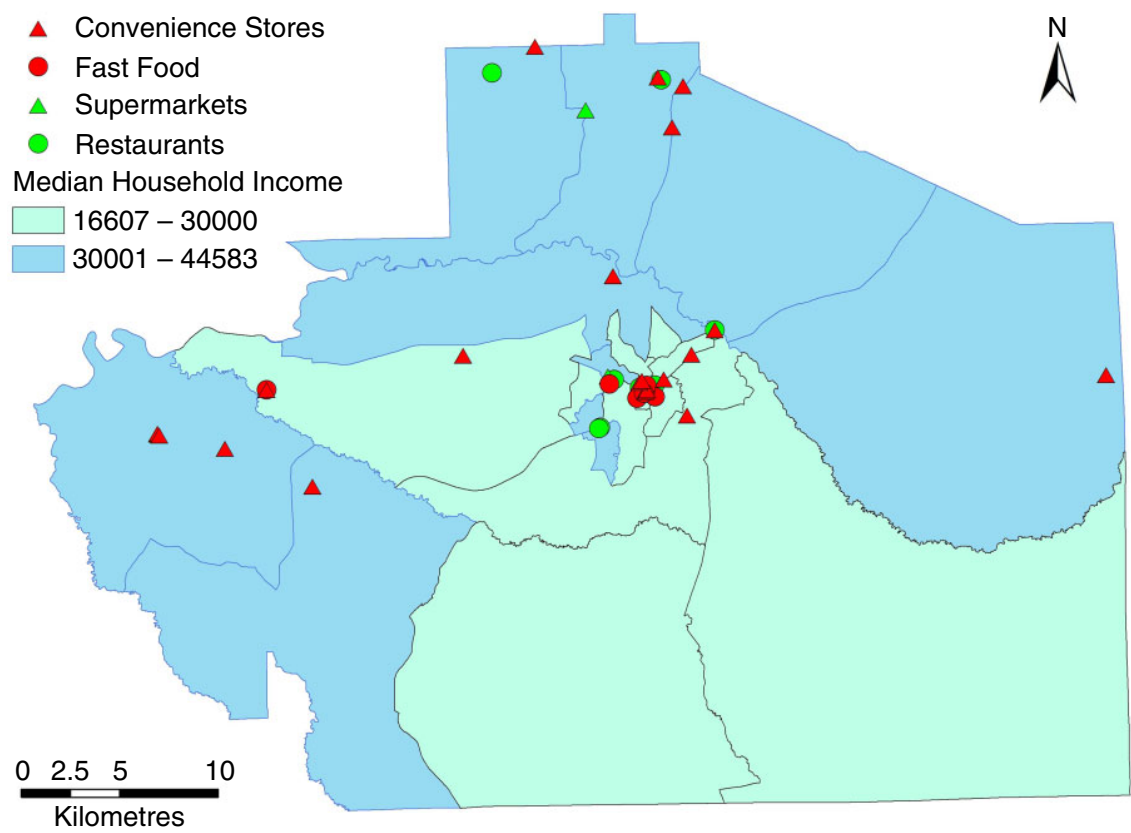

lation is majority and median household income is over $\$ 30000$ has the lowest overweight and obese rate.

This research enriches the literature from the following three perspectives. First, this study addresses a serious health issue, high prevalence of childhood obesity of low-income rural African American children, in the understudied Black Belt region of Alabama. The analytical findings based on 613 African
American students at four elementary schools provide valuable information for better understanding the patterns and potential risk factors of overweight and obesity of this population group. Second, an approach centred on GIS and statistics was applied to integrate spatial and non-spatial data and to assess the spatially continuous food environments. It attempts to minimize the problems of the distance-based and density-based 
approaches in previous studies (Burdette \& Whitaker 2004; Moore et al. 2008) through evaluating the probabilities that children patronize four types of food outlets. The application of mixed-methods makes a step forward to comprehensively evaluate food environments and examine its impacts on childhood obesity (Walker et al. 2010). Third, this research has practical and policy implications. The research findings suggest the need for planning and zoning policies aiming to improve food environments of low-income minority communities, and inform parents and schools to pay more attention to children's eating behaviours and reduce the negative impacts of unequal community food environments on children's weight status.

This study has a few limitations. First, only locations and sizes of food outlets were considered to assess food environments, while the quality and choices of food in these food stores should be also included. Second, we assess the community food environment by estimating the possibilities of children patronizing these food outlets with location modelling. In a future study, the surveyed children's eating behaviour data could further improve our understanding of the complex interactions between demographic factors, school effects, community food environments and children's weight status.

\section{Key messages}

- In Alabama's Black Belt region, nearly half of the children from rural African American families are overweight or obese.

- The quality of community food environments is associated with sociodemographic factors.

- Children living in healthier food environments have lower chance of being overweight or obese than those living in poorer food environments.

- Children's weight is greatly influenced by community food environments, sociodemographic factors and the context effect of schools.

\section{Funding}

We would like to acknowledge the funding of the Auburn University Intramural Grants Program (101503-137060-2052).

\section{References}

Barone, J. A. (2005) Historical presence and distribution of prairies in the Black Belt of Mississippi and Alabama. Castenea, 70, 170-183.
Burdette, H. L. \& Whitaker, R. C. (2004) Neighborhood playgrounds, fast food restaurants, and crime: relationships to overweight in low-income preschool children. Preventive Medicine, 38, 57-63.

Burns, C. M. \& Inglis, A. D. (2007) Measuring food access in Melbourne: access to healthy and fast foods by car, bus, and foot in an urban municipality in Melbourne. Health and Place, 13, 877-885.

Carroll-Scott, A., Gilstad-Hayden, K., Rosenthal, L., Peters, S., McCaslin, C., Joyce, R. \& Ickovics, J. (2013) Disentangling neighborhood contextual associations with child body mass index, diet, and physical activity: the role of built, socioeconomic, and social environments. Social Science \& Medicine, 95, 106-114.

Centers for Disease Control and Prevention (2012) About BMI for children and teens. Available at: http://www.cdc.gov/healthyweight/ assessing/bmi/childrens_bmi/about_childrens_bmi.html (last accessed 10 November 2012).

Cory, A. (2007) The Influence of Home, School, and Community Contexts on Childhood Obesity: A Multilevel Study. University of Illinois at Chicago, Chicago, IL, USA.

Davy, B. M., Harrell, K., Stewart, J. \& King, D. S. (2004) Body weight status, dietary habits, and physical activity levels of middle school-aged children in rural Mississippi. Southern Medical Journal, 97, 571-577.

Field, A., Carlosa, S. J., Barrtaylor, C., Berkey, C., Frazier, L., Gillman, M. \& Colditz, G. (1999) Overweight, weight concerns, and bulimic behaviors among girls and boys. Journal of the American Academy of Child \& Adolescent Psychiatry, 38, 754-760.

Frank, L., Saelens, B., Chapman, J., Sallis, J., Kerr, J., Glanz, K., Couch, S., Learnihan, V., Zhou, C., Colburn, T. \& Cain, K. (2012) Objective assessment of obesogenic environments in youth, geographic information system methods and spatial findings from the neighborhood impact on kids study. American Journal of Preventive Medicine, 42, e47-e55.

Franzini, L., Elliott, M. N., Cuccaro, P., Schuster, M., Gilliland, J., Grunbaum, J. A., Franklin, F. \& Tortolero, S. R. (2009) Influences of physical and social neighborhood environments on children's physical activity and obesity. American Journal of Public Health, 99, 271-278.

Glanz, K., Bader, M. D. M. \& Lyer, S. (2012) Retail grocery store marketing strategies and obesity: an integrative review. American Journal of Preventive Medicine, 42, 503-512.

Gordon-Larsen, P., Nelson, M. C., Page, P. \& Popkin, B. M. (2006) Inequality in the built environment underlies key health disparities in physical activity and obesity. Pediatrics, 117, 417-424.

Grow, M. G., Cook, A. J., Arterburn, D. E., Saelens, B. E., Drewnowski, A. \& Lozano, P. (2010) Child obesity associated with social disadvantage of children's neighborhoods. Social Science and Medicine, 71, 584-591.

Holsten, J. (2008) Obesity and the community food environment: a systematic review. Public Health Nutrition, 12, 397-405.

Huff, D. L. (1963) A probabilistic analysis of shopping center trade areas. Land Economics, 39, 81-90.

Kowalski, K., Crocker, P. \& Donen, R. (2004) The Physical Activity Questionnaire for Older Children (PAQ-C) and Adolescents (PAQ-A) 
Manual. Available at: http://www.dapa-toolkit.mrc.ac.uk/ documents/en/PAQ/PAQ_manual.pdf (last accessed 10 January 2013).

Lanigan, J. D. (2010) The substance and sources of young children's healthy eating and physical activity knowledge: implications for obesity prevention efforts. Child: Care, Health and Development, 37, 368-376.

Leung, C. W., Laraia, B. A., Kelly, M., Nickleach, D., Adler, N. E. \& Kushi, L. H. (2011) The influence of neighborhood food stores on change in young girls' body mass index. American Journal of Preventive Medicine, 41, 43e51.

Li, Y. \& Liu, L. (2012) Assessing the impact of retail location store performance: a comparison study of Wal-Mart and Kmart stores in Cincinnati. Applied Geography, 32, 591-600.

Mathews, S. A. (2012) Thinking about place, spatial behavior, and spatial processes in childhood obesity. American Journal of Preventive Medicine, 42, 516-520.

McMurray, R. G., Harrell, J. S., Bangdiwala, S. I. \& Deng, S. (1999) Cardiovascular disease risk factors and obesity of rural and urban elementary school children. The Journal of Rural Health, 15, 365-374.

Moore, L., Diez Roux, A., Nettleton, J. \& Jacobs, D. J. (2008) Associations of the local food environment with diet quality - a comparison of assessments based on surveys and geographic information systems: the multi-ethnic study of atherosclerosis. American Journal of Epidemiology, 167, 917-924.
Morland, K. \& Evenson, K. (2009) Obesity prevalence and the local food environment. Health and Place, 5, 491-495.

Oreskovic, N. M., Kuhlthau, K. A., Romm, D., Nicolas, M. \& Perrin, J. M. (2009) Built environment and weight disparities among children in high- and low-income towns. Academic Pediatrics, 9, 315-321.

Procter, K. L., Rudolf, M. C., Feltbower, R. G., Levine, R., Connor, A., Robinson, M. \& Clarke, G. P. (2008) Measuring the school impact on child obesity. Social Science and Medicine, 67, 341-349.

Tobler, W. (1970) A computer movie simulating urban growth in the Detroit region. Economic Geography, 46, 234-240.

United States Census Bureau (2010) 2010 Census Data. United States Census Bureau. Available at: http://www.census.gov/2010census/ data/ (last accessed 20 November 2012).

Velde, S., Bourdeaudhuij, I., Thorsdottir, I., Rasmussen, M., Hagströmer, M., Klepp, K. \& Brug, J. (2007) Patterns in sedentary and exercise behaviors and associations with overweight in 9-14-year-old boys and girls - a cross-sectional study. BMC Public Health, 7, 16.

Walker, R. E., Keane, C. \& Burke, J. (2010) Disparities and access to healthy food in the United States: a review of food deserts literature. Health and Place, 16, 876-884.

Zhang, X. Y., Lu, H. \& Holt, J. B. (2011) Modeling spatial accessibility to parks: a national study. International Journal of Health Geographics, 10, 1-14. 